\title{
Perceived Readiness of Educated Youth towards Ethnic Integration in Sri Lanka
}

\author{
M.S. Dimuthu Kumari ${ }^{1 *)}$ \\ ${ }^{1}$ Department of Public Administration, Faculty of Management Studies and Commerce, \\ University of Sri Jayewardenepura, Gangodawila, Nugegoda, Sri Lanka.
}

Received: 2020-10-23; Accepted: 2021-03-02; Published: 2021-04-30

\begin{abstract}
Sri Lanka is a multi-ethnic society hence the ethnic integration has been a hot topic for decades. By 2021, it has been 73 years after the independence from British empires, however, natives still struggle for the reconciliation among themselves. Often occurred ethnic clashes usually account for a huge social and economic cost. Various scholars have highlighted that youth is highly active in initiating ethnic clashes. And, it is quoted specifically for the 'Educated youth' in Sri Lanka context. Therefore, this study explores the perceptions of 'multi-ethnic, educated youth' in heightening ethnic integration in Sri Lanka. This study utilized quantitative research approach and survey method. Primary data was mainly used for the study and collected through an online questionnaire. 100 multi-ethnic youth who are studying in higher education institutions in Sri Lanka selected as the sample using random sampling technique. The readiness of respondents was basically measured through their perceptions with respect to the social integration model proposed by Awang et al (2019). Descriptive statistics were used in analyzing data. The results showed that the overall readiness of educated youth in promoting ethnic integration is high in Sri Lanka context. The respondents are almost ready for the social acceptance and cultural appreciation levels of the model. However, they have showed, relatively a slight attraction towards compromisation and adaptation levels for which a high degree of ethnic tolerance is required. Therefore, it can be concluded that the majority of educated youth are social extroverts and are aware the importance of integration. However, since they showed a little attraction towards the upper layers of integration pyramid, there is a need of re-evaluating existing social integration policies. So that, some policy recommendations are suggested to enhance more operational activities in reconciliation process to reach the upper levels of ethnic integration (compromization and adaptation) in Sri Lanka context.
\end{abstract}

Keywords: Perceived Readines; Educated Youth; Ethnic Integration; Policy Implications

How to Cite: Kumari, M.S.D., (2021). Perceived Readiness of Educated Youth towards Ethnic Integration in Sri Lanka. Journal of Contemporary Governance and Public Policy, 2(1), 31-44. https://doi.org/10.46507/jcgpp.v2i1.28.

Permalink/DOI: https://doi.org/10.46507/jcgpp.v2i1.28 


\section{Introduction}

Sri Lanka is a heterogeneous society with an extremely diverse population in terms of ethnicity, religion, language, and culture. The country is relatively a small island with twenty-two million people. It has been home to many ethnic groups such as the Sinhalese, the Tamils, the Moors, and the Burghers, yet, the ethnic mix is dominated by the Sinhalese acquiring $74.9 \%$ of the total population. The Sri Lanka Tamils, who mostly be inherent in the North and East provinces of the state are considered as the largest minority group amounting to $11.1 \%$ of the total population. The Moors, descendants of early Arab traders are considered as the third largest ethnic group amounting to $9.3 \%$. The rest, a $4.7 \%$ is comprised of some other minor ethnic groups such as Indian Tamils, Burghers, and Malays, etc. (Department of Census and Statistics, 2012). Moreover, population has been religiously separated themselves as Buddhists (69\%), Hindus (16\%), Islam (7\%) and Christians or Protestants (8\%). Each of these groups has its own culture including the identity, customs, traditions, and languages. Since ethnic diversity makes both creativity and conflicts all the time, Sri Lanka has no exception.

The first ethnic tension was recorded in 1915 with the riots between Sinhalese and Sri Lanka Moors. Thereafter, Sri Lanka has immensely suffered for many decades due to the conflicts among different ethnic groups. There was a vicious racial war among the Sinhalese and minority Tamils for 27 years from 1983-2009. To further state, many anti-Muslim riots have been emerged over the past, but, currently the frequency is on the rise. It was recorded several minor clashes in 2014, 2018 and 2019. Making things worse, in 2019, there was a severe attack on the innocent Christian churchgoers on the Easter Sunday by a group of Muslim religious extremists. These continuous events evident that the social integration among different ethnic groups has been yet a challenging task for Sri Lanka. Government and some other parties including NGOs and civil society activists are taking various measures to enhance the ethnic integration in the country, however as noted by many scholars there is long way to go. Many of the recently occurred ethnic clashes in Sri Lanka, were initiated and continued under the leadership of youth, particularly, the educated youth.

Gap Analysis - There are two extreme viewpoints in literature about the youth's involvement in the peace building and integration process. A growing volume of previous studies discuss the contribution of youth as a pivotal agent of national cohesion and peace (McEvoy-Levy, 2012; Saleem, 2015). By contrast, some others have highlighted that youth is highly active in initiating ethnic clashes (Hettige, 2004; Lecamwasam, 2015; Peiris, 2008) and have noted the youth as a threat for the peace and stability of countries (Hendrixson, 2004). Briain 0., (2019) has noted that ethnic wars would not be possible without youth. The world's youth populace has indeed been on the upsurge and it is expected to have 72 million more youth by 2025 (UNESCO and Youth Strategy, 2014). Yet, researchers have proven a higher statistical risk of future conflicts in the countries where there is relative a high youth population (Urdal, 2006). Literature shows (Anderson \& Stephenson, 2018; McCorley, 2013; Zeitzoff, 2017) that the youth is easily mobilized and exposed to these movements through the social media in recent years. 
Similar to the second argument, youth often portrayed and stereotyped as violent actors in Sri Lanka context for decades (Regional Centre for Strategic Studies in Sri Lanka, 2019).

Sallah \& Kennedy (2015) said that the 'race' and 'ethnicity' matters when people integrate in to the structures of the society. As noted by (Komalasari \& Saripudin, 2017) the 'attitude of tolerance' and 'readiness to be integrated' are important indicators of cohesion success among the other factors. Therefore, it is really worth enough to understand in advance, that how people perceive ethnic harmony and integration in societies.

There are some studies which explore the perceptions of youth towards ethnic integration, peace and reconciliation (Awang, Ahmad, Mumpuniarti, \& Abdul Rahman, 2019). However, these perceptions could be vary based on some demographic factors of the youth like their age, gender, education level, family status etc. Yet, no sufficient evidences were found, which examine the differences of youth perceptions on ethnic integration based on different demographic characteristics. Education sector as a place where ethnic discriminations mostly happen. Therefore, the researcher intended to examine the perception of the 'multi-ethnic educated youth' and thereby, to understand what is their readiness level towards the ethnic integration in the society.

Indeed, defining youth is problematic in any context. Definitions on youth are often based on age and differ across countries. The UN describes youth as individuals aged among 15 and 24. However some have argued that the youth is socially constructed and there is nothing about the age.
Therefore, they identified the youth as a transition period from childhood to adulthood. Anyway, in Sri Lanka, the National Youth Policy defines youth as the population aged 15 to 29 years. According to the 2012 statistics, the Sri Lanka youth population has been estimated as approximately 4.4 million (23\%) of the total population. Also, the word 'educated' has been contrarily defined throughout the literature. Harvard university defines a person to be educated only when he/she should possess a deep understanding of themselves and looking at the way how they fit into the world. A person is considered to be educated when he can apply his gained knowledge and skills positively in community life (Yadev, 2004). In this study an educated person is identified as one who has undergone a sufficient amount of knowledge and skills through the formal channel of education system. Therefore, the young people who are studying in a higher education institutions were selected as respondents since this study particularly focuses on the readiness among the 'educated' youth.

Hence, the intention of this study is to explore the perceived readiness of educated youth in boosting ethnic integration in Sri Lanka. Exploring the level of readiness is essentially important because the success of social integration policies and programs is depending on peoples' willingness to adopt them. Therefore, a group of educated youth was randomly selected form higher education institutions representing main three ethnic groups in Sri Lanka for this study.

State of Art - To better understand the discussion carried out in this paper, the author provides some information regarding the key 
discussion concepts like integration, social integration, ethnic integration and ethnic integration models. Accordingly, the word integration is pertinent to any area that connects diverse proxies into the whole social system (Studijo, 2005). Many of the modern-day researchers and theorizers believe that integration is not an administrative, bureaucratic, or legal issue, but it is completely a social issue (Kamali, 1999). According to Cruz- Sao (2008) social integration is a progression in creating harmony, inclusion, and partaking at every levels in society, where everybody come from different backgrounds are practicing their beliefs freely. social integration refers to the principle by which individuals are bound to each other in the social system with interactions (Beresnevièiûtë, 2003). There are multiple ways of understanding the concept, 'social integration'. 1) It denotes the idea of inclusion; where the same opportunities and privileges are ensured for all people, more specifically, becoming more integrated denotes enhancing life chances, 2) It entails the idea that increasing integration has a negative meaning, conjuring up the image of an unwanted burden of uniformity. 3) It defines the established shapes of human relations in any given society. However, social integration, in this study is defined as promoting harmonious interaction and solidarity among different social groups in the society like various ethnic groups, minority groups and migrants.

Hence, ethnic integration is identified as a key concept under the broader umbrella called 'social integration'. Ethnic integration is identified as a popular theme of discussion under the social integration (Naldi, Muchtar, Anwar, Putra, \& Luthfi, 2019). The viewpoints of social integration consist of analyzing the diversity of ethnic groups' activities and relationships, using quantitative and qualitative aspects of relational structures (Studijo, 2005). According to Giddens (2012) ethnicity is a societal phenomenon, which has no base in human biology. He further states that the ethnicity denotes the cultural conducts and stances of a community, which identifies them as a unique social group. As noted by Vida, B. (2003), integration came to overlook the ethnic policy discourse in many countries of Eastern Europe after 1990.

Since integration theories sharpen the lens of many researchers and scholars in the field of ethnic studies (Slootman, 2018), a few theories have been discoursed below namely, the assimilation theory, melting pot theory and cultural pluralism theory. The assimilation theory stresses that immigrants or minorities adjust their unique language, dress codes, lifestyles and other cultural outlooks as step of integrating with the novel social order. Giddens and Phillip, (2012) noted that these minorities are prepared to give up their own culture and embrace the dominant culture to a larger extent. Warner and Srole, cited by Slootman (2018) highlighted that the theory of classic assimilation assumes that immigrants finally adapt to the new culture. They will become increasingly 'similar' and will eventually be seamlessly incorporated into mainstream society (Alba \& Nee, 1997). Anyhow Slootman, (2018) asserts that 'assimilation' theory is lack with capturing the experiences of minority climbers. Melting pot approach asserts that minority ethnic groups become mingled to create new, evolving cultural patterns. According to Giddens (2012) this 
theory is based on mixing together diverse cultural traditions to create novel cultural forms. Authors have accredited this as a most desirable result of ethnic diversity. Customs and traditions of ethnic minorities are not abandoned, but contribute to a continually transforming social milieu (http://www.imej.wfu.edu/). The hybrid forms of foods, fashion, styles, artifacts including music and architecture are real examples for the manifestations of the melting pot approach. Cultural pluralism theory argues that the true development of a society is feasible only under a situation where different subcultures are equally acknowledged. This approach considers all ethnic minority groups as equivalent stakeholders in society, meaning that they are free to enjoy the same social privileges as the majority population. Ethnic differences are respected and recognized as a favorable component of larger national life. The cultural pluralism concept further mentioned that all ethnic groups preserve cultural differences whilst enjoying the wide-ranging social life (Giddens and Phillip, 2012).

As shown in figure no (i), Awang et al (2019) discusses a model of ethnic integration using four main constructs namely; 1) social acceptance, 2) compromization, 3) cultural appreciation and 4) cultural adaptation.

\section{Social Acceptance}

- Tolerate

- Visit others

- Sensitivity

- Openness

- Positive thinking

\section{Cultural Adaptation}

- Practicing aspects of other cultures

- Joining ceremonies of others

- Use unique languages of others

- Use traditional dress-codes of others

- Other ethnic performance

\section{Compromization}

- Compromise

- Giving permission

- Positive views

- Negotiation

- Honesty

\section{Cultural Appreciation}

- Appreciate

- Feeling of Pride

- Volunteerism

- Communication medium

- Sense of belongings

Figure (i) : A model of ethnic integration

Source: Awang et al (2019)

According to figure (i), there are four main constructs in this model. The ability of accepting and tolerating the differences and diversities in other groups is called as 'Social acceptance'. This is an individual behavior and eventually it fits with group behavior. Awang et al (2019) highlighted that social acceptance is an important channel in enhancing tolerance among groups.
Ethnic tolerance refers to an objective and permissive attitude towards other ethnic groups of people despite their beliefs, practices, opinions, and racial origins. According to Taib (1984) cited by Awang (2019), the levels of tolerance will increase when the opportunity to interact with others can be successfully achieved. The next construct 'compromization' only permits through the ethnic 
tolerance. Compromization refers to the settlement of variances having mutual concessions. It is an agreement reached by parties with the adjustment of conflicting claims, principles, and by reciprocal reform of demands (Awang et al, 2019). The author discusses the next construct as the 'cultural appreciation'. It is the process of having wisdom on other cultures with courtesy and respect. It also refers to borrowing of elements in other cultures having perceived their cultural significance. The next construct, 'cultural adaptation' exists when a person is enjoying a comfortable feeling after adapting to a new culture. It would be a difficult situation for a person since he or she needs to pass different stages of emotions during this process. According to the famous model of $U$ curve on cultural adaptation, those stages are:1) honeymoon stage, 2) culture shock stage, 3 ) recovery stage, and 4) adjustment stage (Black \& Mendenhall, 1991).

However, none of above theory or model discusses the behavior or perceptions of youth in ethnic integration process. Therefore, current study tries to understand the perception of youth-particularly the educated youth, towards ethnic integration. Therefore, the findings of the current study would be useful to strengthen the existing body of knowledge. Yet more further studies are needed to identify the behavior and perception differences of youth among the other age groups and with respect to the other demographic characteristics.

\section{Research Methods}

This study aimed to identify the perceived readiness of educated youth towards the ethnic integration in Sri Lanka. The readiness was explored under the ethnic integration model proposed by Awang et al
(2019). The readiness of educated youth was basically measured using four dimensions of aforementioned social integration model namely 1) social acceptance 2) compromization 3) cultural adaptation and 4) cultural appreciation. This paper recognizes these dimensions as 'levels of social integration' rather than independent variables. Then, the readiness level was examined using 20 elements extracted from above four constructs of the social integration model.

This is a quantitative study and utilized online survey research design. Primary data were collected from 100 multi-ethnic youth whose aged between 15 and 29 years and who study in higher education institutions in Sri Lanka. The published information in UN reports, World Bank reports, other relevant local statistics and journal articles were used as secondary data. A structured questionnaire was distributed via an online survey, among randomly selected 220 young people in higher education institutions in Sri Lanka and only 100 responses were received. Though the proportion is not equal, the sample represents respondents from all three main ethnic groups namely, the Sinhalese, the Tamils and the Muslims. However, the unit of analysis is considered as an individual educated youth. The questionnaire includes the statements regarding the dimensions of the aforementioned social integration model. Five items were used to inquire the perception of youth towards each variable so that altogether 20 statements were included in the questionnaire in a 5 point Likert scale in which the highest level of agreement was marked as 05 and lowest as 01 . The validation of measurement properties (reliability and validity) was already ensured by previous studies. Descriptive 
statistics (mean and standard deviation) were used in analyzing data.

\section{Results and Discussion}

\section{Discussion on Demographic profile of the sample}

Response rate of the study was 45\%. Respondents comprised the Sinhalese (59\%), the Moors (32\%) and Tamils (9\%) respectively. And majority (54\%) of them aged between 25-29. The religion of the respondents was recorded as $52 \%$ of Buddhism, 32\% of Muslim, 9\% Hindus and $7 \%$ of Christians. $59 \%$ of the respondents were female and rest (41\%) were male youth. Majority (73 $\%)$ of them were coming from urban and sub-urban areas. More than half $(60 \%)$ of the sample was employed and the rest $(40 \%)$ is studying in universities, higher education institutions or schools. Majority (73\%) of them have followed their school education in Sinhalese and the $15 \%$ of them have followed their education in English whereas the rest $(12 \%)$ has followed it in Tamil medium. Most of them have responded that they are fluent in Sinhala or English as communication media.

\section{Discussion on results}

The overall perceived readiness was measured using four variables as suggested by previous

\begin{tabular}{|ll|}
\hline Readiness level & insights of cultural pluralism theory. \\
\hline Readiness for social acceptance & Mean score \\
\hline Readiness for cultural appreciation & 4.144 \\
\hline Readiness for ethnic tolerance and compromising & 4.126 \\
\hline Readiness for cultural adaptation & 3.786 \\
\hline Overall readiness & 3.518 \\
\hline
\end{tabular}

Source; field data, 2020 studies, which are shown in figure no. (i).

According to the statistics in table no. (i), youth is highly ready for the acceptance of social integration and cultural appreciation levels recording a mean score of 4.1. However, compared to those levels, they showed a little attraction towards compromisation and cultural adaptation levels recording relatively a less mean values; 3.7 and 3.5 respectively.

These results are consistent with a past study done by Awang et al (2019) regarding social integration practices between multi ethnic youth in Malaysian context. In contrast, a study done has found that the Sinhalese, the largest ethnic group in the country, to a large extent do not exhibit a sense of friendship with other minority ethnic groups in Sri Lanka. However, in both cases, they have ignored the education level of the sample.

As proposed by the cultural pluralism theory a higher level of willingness for social integration is very important for a true development of a society. Since the overall readiness amounts to mean score of 3.8 , it reflects that the majority of educated youth are social extroverts. They and have understood the importance of integration irrespective of socially constructed diversities. So this finding of Sri Lanka context is supported for the insights of cultural pluralism theory. 
Note: The above table shows the overall perceived readiness of youth towards ethnic integration in Sri Lanka which is recorded as mean score of 3.8 in a five -point scale. Also, they are extremely ready for the social acceptance and cultural appreciation levels, recording the mean scores of 4.1. However, compared to those, they showed a little attraction towards compromisation and cultural adaptation levels recording a relative least mean score of 3.7 and 3.5 respectively

Table (ii) : Mean and Standard deviation values for individual indicators

mean S.D.

\section{Social Acceptance level}

willing to tolerate teachings in other religions

$3.86 \quad 1.08$

like to have friends in other ethnic groups and meet them

$4.40 \quad 0.95$

take care of other ethnics' sensitivities(I don't use words which hurt other 4.35 ethnic groups)

open to discuss various things with a person from different ethnic $4.14 \quad 1.00$ background

\section{Compromising \& tolerance level}

ready to listen ideas and opinions of friends in other ethnic groups and come $\quad 4.00 \quad 1.06$ in to agreements together

allow different religious groups to follow their religious faith in my area $\quad \begin{array}{lll}3.82 & 1.13\end{array}$

ready to talk various matters honestly with people in different ethnic groups $3.96 \quad 1.05$

actively participate negotiations when there are conflicts and issues of racism $3.19 \quad 1.26$

\begin{tabular}{lll}
\hline positively consider values of other cultures when organizing things & 3.96 & 1.03
\end{tabular}

\section{Cultural Adaptation level}

\begin{tabular}{lcc}
\hline Practicing and keen on some parts of other cultures & 3.96 & 1.25 \\
\hline Joining to social/religious ceremonies of others & $\mathbf{2 . 8 2}$ & 1.28 \\
\hline Use Languages of other ethnic groups & 4.09 & 1.05 \\
\hline wear traditional attires of other ethnic groups & $\mathbf{2 . 8 5}$ & 1.20 \\
\hline enjoy in music, dramas and art performances of other ethnic groups & 3.87 & 1.21
\end{tabular}

\section{Cultural Appreciation level}

appreciate contribution of other ethnic groups in country's development

$4.42 \quad 0.96$


feel proud of economic, social and cultural success of other ethnic groups 3.87 within my country

happy about volunteers/stars in other ethnic groups representing the 4.35

0.99 country in different fields (arts, music, sports, innovation etc)

Try for using a shared language (English) when talking to other ethnic groups 4.11 1.10

participate for social events enthusiastically despite of ethnic backgrounds 3.88

1.07

Source : field data, 2020

Note: This table shows the perceived readiness of youth for each items under the main four constructs of the selected ethnic integration model. As per the field data, the highest perceived readiness is recorded for an indicator (ready to associate multi ethnic friends) under the "social acceptance" construct. Meanwhile, the lowest readiness was recorded for an indicator (Attending social/religious ceremonies of others) under the construct of "cultural adaptation'.

Among all the indicators, two items are significantly show a higher level of perceived readiness towards integration. The first one is 'the readiness to acceptance of peers from other ethnic groups (4.40) and the other one is for appreciating contribution done by people in other ethnic groups for socio-economic progress (4.42) of the country. Similar kind of observation has done by the UN (2018) because they have found that the majority of youth have national interest and they would like to identify themselves only as 'Sri Lankas' without referring to any ethnicities. Also, the respondents showed a higher level of perceived readiness (mean $=4.09)$ to use languages of other ethnic groups. This is a positive trend since the National Youth Policy of Sri Lanka (2014), itself indicates the language as a barrier for interaction among youth of different communities.

Yet, they have almost rejected to attend the religious and social events of other ethnic groups recording the least mean value of 2.82. An Iranian study done by MojdehJamshidi and Abdolkhani (2016), has also found that the factors like 'religion and spiritual heritage' of different groups highly disintegrate people. Some other indicators like readiness to use traditional attires of other ethnic groups (2.85), readiness for negotiations in matters of racism (3.19), and readiness to allow other ethnic groups to practice their religious faith in own area (3.8) have recorded smaller values compared to others. However, Naldi $H$. et al. (2019) has found that people are interested in intermingling functions, foods and attires of other ethnic groups in Indonesian context. At the same time, higher level of readiness has shown to the indicators like taking care of other ethnics' sensitivities (4.35), appreciating volunteers/stars in other ethnic groups who represent the country in various fields like sports, music, innovations (4.35). A similar finding was reported by Naldi $H$ (2019). They have found a higher level ethnic integration through the activities like arts and sports.

When analyzing the results, these figures shows that the respondents are almost agree with accepting ethnic differences and also, appreciating the favorable social contribution of other ethnic groups to the country. However, they have little hesitation towards compromising and cultural adaptation levels in the 
current context. Therefore, it can be concluded that majority of youth people have almost understood the need of social integration, however, are not, yet completely ready for the total integration among themselves. However, this educated youth group cannot be directly identified as extremists in any end. Since Sri Lanka is still experiencing some destructive events due to ethnic disintegration, the real situation of the country complies with the results. Anyhow, the sample size would be the main limitation of the study. The results might be changed under a larger sample size.

\section{The pyramid shape of ethnic integration levels}

The perceived readiness level of respondents (the total score of agreement to the given statements) were shown differently for the items under each variable in the questionnaire. If any respondent has scored more than $75 \%$ of the total score for a one variable, he/she was considered to calculate the composition of that particular 'Readiness level'. That total score of each respondents was considered to calculate the composition of each Readiness level. Accordingly, most of the respondents were ready for the 'social acceptance level' (85 out of 100 respondents have scored more than 75 marks for the acceptance level), and the majority is for appreciation level (79 out of 100 respondents have scored more than 75 marks for the appreciation level), few (56 out of 100) for compromising level and relatively a little (48) amount of youth were ready for cultural adaptation level when considering their perceptions. Therefore, the composition of respondents to each level of ethnic integration can be presented in a pyramid shape rather than individual variables standing independently. Hence, the box type model adapted by Awang et al (2019) rearranged (see figure ii) in to a pyramid shape with the findings of the current study. However, this has to be checked with the results of a comparative study using different social contexts to see whether the similar shape of results is derived.

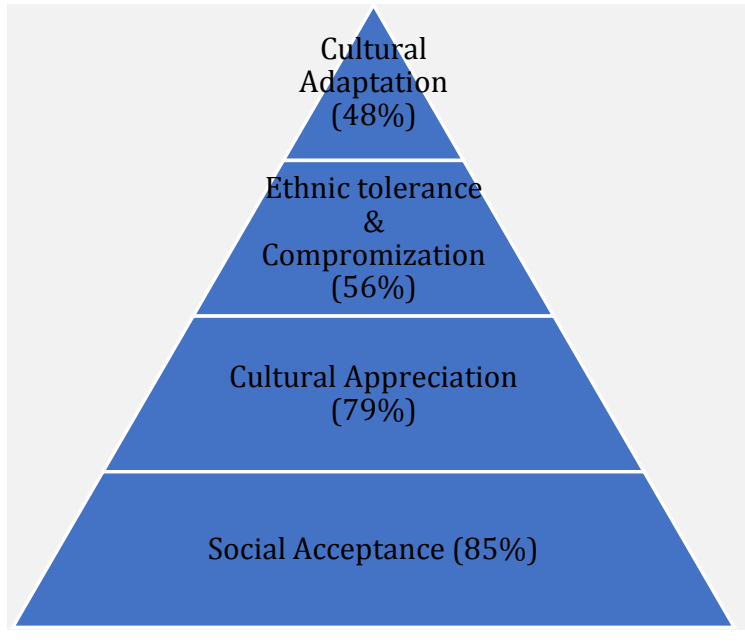

Figure (ii): Perceived Readiness of respondents for the levels of Ethnic integration

As shown in figure no (ii), the educated youth have positive perceptions towards ethnic integration as a whole. However, the perceived readiness is higher in the lower stages and lesser in the upper stages of the model. It denotes that they tend to hesitate for integrating with other ethnicities during the upper levels (adaptation and compromization) which can be identified as the situations in real world. This kind of situation has shown by a past research findings of an independent progress study of youth and peace conducted by United Nations. UN says that attitudes/feelings of nearly half of the youth towards other ethnic groups are friendly. However, still, there is a long way to go in building interethnic relations among youth and in 
dispelling an 'enemy image' towards other ethnic groups in the real world.

\section{Recommendations for enhancing ethnic integration among youth}

1) Keep a stable national level strategy on ethnic integration in all time

It is highly important to have a national policy on ethnic reconciliation attempts. Yet, in Sri Lanka context, there were different approaches of different governments throughout the history. However, the ethnic integration policies devised by one government will disappear when the ruling party changed. Therefore, keeping a fixed policy to deal with ethic integration is vital for social harmony in the country. A national policy can be formulated to establish a unified society where individuals with different linguistic and cultural backgrounds actively join in society. And under such broader national policy, various youth specific objectives can be introduced to cover a wide range of activities like opportunities for multi-ethnic youth initiatives, involvement of young people in youth work, youth awareness workshops under the title of human rights education, cultural diversity, marginalized groups, prevention of hate speech, etc. The continuous happenings of such events will yields positive impact on ethnic integration among youth people in the long run.

\section{2) Use sophisticated 'multiculturalism'} concept in education sector

According to Giddens and Phillip (2012) this concept 'multiculturalism' stresses the significance of national identity and nationwide laws, but also nurturing of connections among various social and ethnic groups. The concept is highly important for Sri Lanka since there are ethnic based schools and curriculums at all levels which could be adversely affected for the segregation among people. Therefore, the policy makers specially in education and higher education sectors has a greater role in this regard. They should take actions to reduce the deviations between curricular in different schools and enrich the entire education system with national values.

\section{3) Encourage ethnic reconciliation ideas via different artifacts}

Youth is highly attracted towards new facets of different artistic creations like songs, drams, films and so on. This is a unique characteristic among the youth irrespective of their ethnicities and cultures. The message of ethnic harmony, therefore, easily can be injected to the mindset of youth through this kind of arts for which youth is highly attracted from the bottom of their hearts. Thus, the artists in different fields has a greater role in this aspect and the media also can contribute to the promotions of the same.

\section{4) Organize social media campaigns to promote ethnic harmony among youth}

Ethnic harmony always yields a positive impact to the society. The integration of diversity floors the path to confirm human rights, thereby, it creates more stable and harmonious societies. So, the policy makers should try to cultivate the ideas regarding this, by every possible method. In the case of youth, they are usually spending a significant amount of their time connecting to social media. Therefore, social media will be an ideal platform to cultivate ideas on ethnic integration. So, the respective bodies 
can take deliberate efforts to promote ideas thorough various mottos, slogans, small video clips and short films through which the heart of the youth could be easily and frequently touched. The government bodies like to the Ministry of cultural affairs, Ministry of education, Ministry of telecommunication and even the Ministry of ethnic reconciliation can work on this end.

5) Introduce youth -led social and economic development programs at the ground level

As shown in the findings of the current study, the acceptance and appreciation levels are almost satisfactory in Sri Lanka context. What we need is to enhance the higher levels of the ethnic integration process. Thus, we need more operationalized programs to improve the interactions, behaviors, civic skills, volunteerism among the multi ethnic youth in the process of country's socio - economic development. Therefore, the policy makers should deliberately design the composition of various village level development committees in a way which represent all the ethnic groups, so that, they are working together to achieve common goals which ultimately tighten the bond among each other.

\section{Conclusion}

This study conclude that the majority of educated youth have already understood the need of social integration. However, they are not, yet completely ready for a total integration among themselves. Though there is a criticism towards the youth, particularly the educated youth, as a source of ethnic disintegration in Sri Lanka, the results reject that opinion, showing an overall positive attitude of respondents regarding ethnic integration. (However, more comprehensive study is yet to be done by expanding the sample size, its' framework and using some other triangulation techniques). Moreover, the willingness towards the upper levels of integration (adaptation, tolerance, compromise etc) is relatively low. Thus, more attention should be given to enhance compromising ability among ethnically diverse youth at community level which ultimately leads to adaptation ability as well. For that, more operationalized policy package is needed to improve the interactions, behaviors, civic skills and volunteerism among the multi ethnic youth in the process of country's social and economic development. Further researches can be suggested to find out whether the overall readiness differ, based on the other demographic factors of the respondents. The findings of the current study would be useful for policymakers, and practitioners in designing and implementing social integration policies.

\section{Acknowledgments}

I would like to thank my colleagues in the Department of Public Administration, Faculty of Management Studies and Commerce, University of Sri Jayewardenepura, Sri Lanka for their support and discussions during the research and article writing process.

\section{References}

Alba, R., \& Nee, V. (1997). Rethinking assimilation theory for a new era of immigration. International Migration Review, 31(4), 826874.

Anderson, C. D., \& Stephenson, L. B. (2018). Mobilizing the young: The role of social networks. Canadian Journal of Political Science, 51(4), 861-880.

Awang, M. M., Ahmad, A. R., Mumpuniarti, \& Abdul Rahman, 
A. A. (2019). Social integration practices among multi-ethnic youths. Kasetsart Journal of Social Sciences, 40(2). https://doi.org/10.1016/j.kjss.2 017.10.004

Beresnevièiûtë, $\quad$ V. (2003). Dimensions of social integration: Appraisal of theoretical approaches. Ethnicity Studies, 2003, 96-108.

Black, J. S., \& Mendenhall, M. (1991). The U-Curve Adjustment Hypothesis Revisited: A Review and Theoretical Framework. Journal of International Business Studies, 22(2), 225-247. https://doi.org/10.1057/palgrav e.jibs.8490301

Briain, O. (2019). Sri Lanka, Ethnic Conflict, and the Rise of a Violent Secessionist Movement. Retrieved from E-International Relations website: https://www.eir.info/2012/11/ 28/sri-lanka-ethnic-conflict-andthe-rise-of-a-violent-secessionist movement/

Cruz-Sao, M. A. (2008). Promoting social integration: Economic, social and political dimensions with a focus on Latin America. Retrieved from United Nations website:

http://www.un.org/esa/socdev/ social/meetings/egm6_social_ integration/documents/Promoti ng_Social_Integration.pdf

Department of Census and Statistics. (2012). Census of Population and Housing, Sri Lanka. Battaramulla.

Giddens, A., \& Philip, W. S. (2012). Sociology. Retrieved from Polity Books website: https://politybooks.com/gidden s7/studentresource/summaries/ Student_Summary_16.asp

Hendrixson. (2004). Angry Young Men, Veiled Young Women Constructing a New Population Threat.
Hettige, S. (2004). Economic Policy, Changing Opportunities for Youth, and the Ethnic Conflict in Sri Lanka. In D. Winslow \& M. D. Woost (Eds.), Economy, Culture, and Civil War in Sri Lanka. Indiana: Indiana University Press.

Kamali, M. (1999). Distorted integration: Problems of monolithic order. Innovation: The European Journal of Social Science Research, 12(1), 81-97.

Komalasari, K., \& Saripudin, D. (2017). A model of living values education-based civic education textbooks in Indonesia. The New Educational Review, 47(1), 139150.

Lecamwasam, N. O. (2015). 'United we stand, divided we fall': a case study of Sri Lanka youth in citizenship development. International Journal of Adolescence and Youth, 20(4), 442-456.

https://doi.org/10.1080/02673 843.2015.1020819

McCorley, C. (2013). Structure, agency and regime change: a comparative analysis of social actors and regime change in South Africa, Zambia and Zimbabwe. Journal of Contemporary African Studies, 31(2), 265-282.

McEvoy-Levy, S. (2012). Youth spaces in haunted places: Placemaking for peacebuilding in theory and practice. International Journal of Peace Studies, 1-32.

Naldi, H., Muchtar, H., Anwar, F., Putra, I., \& Luthfi, Z. F. (2019). Social Integration Model among Ethnics in Indonesia. 1st International Conference on Education Social Sciences and Humanities (ICESSHum 2019), 805-811. Atlantis Press.

Peiris, G. H. (2008). Sri Lanka: Youth unrest and inter-group conflict 
(Vol. 19). New Delhi: Bulwark Books.

Regional Centre for Strategic Studies in Sri Lanka. (2019). The Potential Role of Young Leaders and Volunteers in Preventing Violent Extremism in Sri Lanka.

Saleem. (2015). Strengthening national integration among educated youth. Journal of Contemporary Studies, 4(1).

Sallah, M., \& Kennedy, R. (2015). 'Race', Ethnicity and Young People. In Socially Just, Radical Alternatives for Education and Youth Work Practice (pp. 169194).

https://doi.org/10.1057/97811 37393593_9

Slootman, M. (2018). Studying ethnic identification. Tools and theories. In Ethnic Identity, Social Mobility and the Role of Soulmates (pp. 13-40). Springer.

Studijo, E. (2005). Dimensions of Social Integration of Ethnic Groups in the Contemporary Society of Lithuania. Retrieved from Etninių tyrimų institutas website: http://www.ces.lt/wpcontent/uploads/2010/03/Etnis kumo-studijos-2005-EN-

IVADAS.pdf

UNESCO and Youth - Strategy. (2014). United Nations Educational, Scientific and Cultural Organization. Retrieved from UNESCO and Youth Strategy website: http://unesdoc.unesco.org/imag es/0022/002271/227150e.pdf

Urdal, H. (2006). A clash of generations? Youth bulges and political violence. International Studies Quarterly, 50(3), 607629.

Yadev, U. (2004). Ethnic conflict in Sri Lanka - Changing dynamics, Policy Studies 32. Retrieved from East-West Center-Washington website:

http://www.eastwestcenterwas hington.org/

Zeitzoff, T. (2017). How social media is changing conflict. Journal of Conflict Resolution, 61(9), 19701991.

(C) 2021 by the Authors. Submitted for possible open access publication under the terms and conditions of the Creative Commons Attribution (CC BY SA) license (https://creativecommons.org/licenses/by-sa/3.0/). 